\title{
New Insight into the Kinetics of Deep Liquid Hydrocarbon Cracking and Its Significance
}

\author{
Wenzhi Zhao, Shuichang Zhang, Bin Zhang, Kun He, and Xiaomei Wang \\ Research Institute of Petroleum Exploration and Development, Beijing 100083, China \\ Correspondence should be addressed to Shuichang Zhang; sczhang@petrochina.com.cn
}

Received 31 March 2017; Accepted 20 July 2017; Published 6 September 2017

Academic Editor: Paolo Fulignati

Copyright ( 2017 Wenzhi Zhao et al. This is an open access article distributed under the Creative Commons Attribution License, which permits unrestricted use, distribution, and reproduction in any medium, provided the original work is properly cited.

\begin{abstract}
The deep marine natural gas accumulations in China are mainly derived from the cracking of liquid hydrocarbons with different occurrence states. Besides accumulated oil in reservoir, the dispersed liquid hydrocarbon in and outside source also is important source for cracking gas generation or relayed gas generation in deep formations. In this study, nonisothermal gold tube pyrolysis and numerical calculations as well as geochemical analysis were conducted to ascertain the expulsion efficiency of source rocks and the kinetics for oil cracking. By determination of light liquid hydrocarbons and numerical calculations, it is concluded that the residual bitumen or hydrocarbons within source rocks can occupy about $50 \mathrm{wt}$.\% of total oil generated at oil generation peak. This implies that considerable amounts of natural gas can be derived from residual hydrocarbon cracking and contribute significantly to the accumulation of shale gas. Based on pyrolysis experiments and kinetic calculations, we established a model for the cracking of oil and its different components. In addition, a quantitative gas generation model was also established to address the contribution of the cracking of residual oil and expulsed oil for natural gas accumulations in deep formations. These models may provide us with guidance for gas resource evaluation and future gas exploration in deep formations.
\end{abstract}

\section{Introduction}

The natural gas accumulations of deep marine strata in China are mainly derived from the cracking of liquid hydrocarbons [1-5]. Previous research believed that natural gas has been mainly derived from accumulated paleoreservoirs of liquid hydrocarbons via cracking [6, 7]. However, the dispersed liquid hydrocarbons could also act as an important source for natural gas accumulations. Residual petroleum refers to those retained in source rocks and along migration pathways. Since there is no systematic evaluation method for quantifying residual petroleum, there remains a great controversy on this issue [8-18]. The amount of residual petroleum in source rocks could be calculated using expulsion efficiency. Pepper and Corvi [9] proposed that liquid hydrocarbons could be expelled from source rocks via kerogen or inorganic pore system, and the greatest expulsion efficiency for marine and lacustrine source rocks could reach $80 \%$, and the residual petroleum in the source rocks is of $5 \%$ 20\%, using the ORGAS model.

Ritter [11] first proposed the application of swellingtheory in expulsion efficiency calculation and demonstrated that different geochemical fractions have different expulsion efficiency and the expulsion efficiency of saturates could achieve as high as $80 \%$. Kelemen et al. [14] discovered chemical fractionation during hydrocarbon expulsion based on the swelling-theory and thus established the Exxon CSCYM model to predict hydrocarbon compositions on the basis of chemical structures and production $[15,19]$. Stainforth [17] thought that hydrocarbon expulsion is achieved by diffusion via organic pore system and set a generation and expulsion model, ShellGenex, including both the transition state theory and the free volume theory. The model suggests that hydrocarbon expulsion is a continuous process with decreasing GOR of the expelled petroleum and increasing density of the expelled oil. The dispersed hydrocarbons that occurred in the migration pathways are even more difficult to quantitative evaluation due to the reservoir and structure condition or the secondary modification of later structural evolution. Zhao et al. [4] demonstrated the significance of dispersed liquid hydrocarbons on gas accumulations and divided them into three occurrence states based on paleostructure: accumulated, half-accumulated, and dispersed. 
TABLE 1: Basic geochemical characteristics of source rock samples.

\begin{tabular}{|c|c|c|c|c|c|c|c|c|c|}
\hline Well & Strata & Depth $(\mathrm{m})$ & Basin & TOC (\%) & $T \max \left({ }^{\circ} \mathrm{C}\right)$ & $S_{1}(\mathrm{mg} / \mathrm{g})$ & $S_{2}(\mathrm{mg} / \mathrm{g})$ & HI (mg/g.TOC) & $R_{o}(\%)$ \\
\hline Chao 73-87 & $\mathrm{K}$ & 834.6 & Songliao Basin & 4.89 & 435 & 1.39 & 42.06 & 860 & 0.5 \\
\hline Da 11 & $\mathrm{~K}$ & 1710 & Songliao Basin & 3.71 & 434 & 0.91 & 30.74 & 829 & 0.5 \\
\hline $\mathrm{Da} 11$ & $\mathrm{~K}$ & 1712 & Songliao Basin & 4.14 & 442 & 0.74 & 36.70 & 886 & 0.6 \\
\hline Da 11 & $\mathrm{~K}$ & 1722 & Songliao Basin & 3.31 & 447 & 0.51 & 27.19 & 821 & 0.8 \\
\hline $\mathrm{X} 28$ & $\mathrm{~J}$ & 1996 & Sichuan Basin & 3.03 & 447 & 2.96 & 12.07 & 398 & 0.9 \\
\hline PL 10 & $\mathrm{~J}$ & 1995 & Sichuan Basin & 2.54 & 449 & 3.65 & 10.21 & 402 & 1.0 \\
\hline PL10 & $\mathrm{J}$ & 1997 & Sichuan Basin & 2.81 & 449 & 2.45 & 10.40 & 370 & 1.0 \\
\hline
\end{tabular}

TABLE 2: The physical characteristics and geochemical compositions of oil samples.

\begin{tabular}{|c|c|c|c|c|c|c|}
\hline \multirow{2}{*}{ Well } & \multirow{2}{*}{ Oil type } & \multirow{2}{*}{ Location } & \multirow{2}{*}{$\begin{array}{l}\text { Density } \\
\left(\mathrm{g} / \mathrm{cm}^{3}\right)\end{array}$} & \multicolumn{3}{|c|}{ Group composition (\%) } \\
\hline & & & & Saturates & Aromatics & Resin + asphaltenes \\
\hline ND 1 & \multirow{3}{*}{ Light oil } & Bohai Bay Basin & 0.76 & 95.90 & 2.34 & 1.76 \\
\hline ZG 6 & & & 0.78 & 78.56 & 20.54 & 0.90 \\
\hline YH 7 & & & 0.79 & 82.06 & 15.47 & 2.47 \\
\hline DH11 & \multirow{2}{*}{ Normal oil } & Tarim Basin & 0.87 & 80.00 & 15.00 & 5.00 \\
\hline YM201 & & & 0.86 & 30.91 & 48.45 & 20.64 \\
\hline LN 1 & Heavy oil & & 0.97 & 29.00 & 31.00 & 40.00 \\
\hline
\end{tabular}

Previous researches on liquid hydrocarbon cracking mainly focused on high temperature cracking mechanisms, and it is generally believed that the liquid hydrocarbons begin to crack and are terminated at about $200^{\circ} \mathrm{C}[20,21]$. Recently, many researches on kinetics of gas generation have been proposed as more and more oil cracking gas accumulations are being discovered [3, 6, 7, 15, 21-29]. Dieckmann et al. [30] obtained kinetic parameters of gas generation at different maturity stages using microscale sealed vessel (MSSV) thermal cracking of the Toarcian Shale and deduced that when the geothermal heating rate is about $5.3^{\circ} \mathrm{C} / \mathrm{ma}$, the initiation temperature of oil cracking happened at $150^{\circ} \mathrm{C}$, with $R o$ of $1.2 \%$, and the peak gas generation corresponds to $180^{\circ} \mathrm{C}$. Tsuzuki et al. [31] proposed that the peak gas generation from oil cracking corresponds to $220^{\circ} \mathrm{C}$, based on the kinetics parameters of cracking experiments of different fractions of oil, and believed that the gas accumulations of oil cracking could only be found beyond $5000 \mathrm{~m}$. Vandenbroucke et al. [32] divided the $\mathrm{C}_{14+}$ fraction into compositions of NSOs, $\mathrm{C}_{14+}$ Aro-1, $\mathrm{C}_{14+}$ Aro-2, $\mathrm{C}_{14+} \operatorname{sat}(n), \mathrm{C}_{14+}$ sat(iso + cyclo), and so forth and calculated the kinetics parameters of each composition. Behar et al. $[33,34]$ calculated hydrocarbon generation potentials under laboratory and natural conditions based on the above kinetic parameters.

In this paper, we discuss the categories of oil occurrences, their cracking mechanism, and gas potential, which can provide a new insight into evaluation of the deep gas resource prospects.

\section{Samples and Experiments}

2.1. Samples. In order to quantify the residual petroleum during the generation process, source rock samples of different maturities are needed. Since the marine strata in China have all experienced deep burial, the organic matters in the source rocks are at mature to overmature stages. Thus, the Cretaceous source rock samples from the Songliao Basin, with relatively low thermal maturity, and the Jurassic source rock samples from the Sichuan Basin, with peak oil generation maturity, were chosen for our pyrolysis experiments. The basic geochemical characteristics of these samples are listed in Table 1.

Eight oil samples for dynamic analysis of thermal cracking and gas generation were obtained from the Tarim Basin and the Bohai Bay Basin, including heavy, normal, and light oils, with densities ranging from $0.76 \mathrm{~g} / \mathrm{cm}^{3}$ to $0.97 \mathrm{~g} / \mathrm{cm}^{3}$. The geochemical compositions of these oil samples are listed in Table 2.

\subsection{Experimental Methods}

2.2.1. Gold Tube Simulation Experiment of Liquid Hydrocarbons. Thermal cracking of the liquid hydrocarbons was achieved using the gold tube simulation apparatus, under the conditions of high temperature and high pressure. The procedures for adding samples into the gold tube were as follows. One side of gold tube $(60 \mathrm{~mm} \times 5 \mathrm{~mm})$ was sealed by welding under constant argon flow condition; then certain amount of samples was added to the gold tube through the other open side. Afterwards, the added tube was fixed in a cold water bath, and the air was swept out by argon flow for 5 minutes. Then, the gold tube was sealed by welding to provide a complete closed environment. The completely sealed gold tube was put into a reaction still, and simulation experiment was performed under the programmed temperature conditions. The sealed gold tube was weighed both before and after the simulation experiment in order to exclude the possibility of potential leakage. 
The gold tube simulation experiment was designed to include two procedures, with heating rate of $2^{\circ} \mathrm{C} / \mathrm{h}$ and $20^{\circ} \mathrm{C} / \mathrm{h}$, heating duration time $(4 \mathrm{~h}, 8 \mathrm{~h}$, and $16 \mathrm{~h}$ ), and thermal cracking under the thermostatic conditions $\left(400^{\circ} \mathrm{C}\right)$, with different reaction medium conditions. The pressure of the reaction system was set at $50 \mathrm{MPa}$, and the deviation range is within $0.1 \mathrm{MPa}$. The temperature and pressure of the reactor were controlled by the computer terminal program, and the range of the temperature deviation is within $0.1^{\circ} \mathrm{C}$.

The collection and quantification of gas from the gold tubes were performed by a custom-made device which was connected to a vacuum pump. Prior to piercing the tube, the gas collection unit was pumped at a residual pressure $(P 1$, $<10^{-3}$ bar). The pressure of the collection unit was recorded after the gold tube was ruptured (P2). The volumes of gas products were calculated according to the following equation: $V=(P 2-P 1) \times V o / P o(V o$ is the volume of gas collection unit and $P o$ is atmosphere pressure).

Identification and quantification of the individual hydrocarbon and nonhydrocarbon gas components were carried out using a two-channel Wasson-Agilent 7890 Series gas chromatograph (GC). The temperature of the heating program for the $\mathrm{GC}$ oven started from $20^{\circ} \mathrm{C}$ to $68^{\circ} \mathrm{C}$ (held isothermal for $7 \mathrm{~min}$ ), then increased to $90^{\circ} \mathrm{C}$ (at a rate of $10^{\circ} \mathrm{C} / \mathrm{min}$ and then held isothermal for $1.5 \mathrm{~min}$ ), and finally reached $175^{\circ} \mathrm{C}$ (at a rate of $15^{\circ} \mathrm{C} / \mathrm{min}$ and then held isothermal for $5 \mathrm{~min}$ ). An external standard was used for the chromatographic calibration. The certified gas standards were prepared at a precision of better than $\pm 1 \mathrm{~mol} \%$ for each component made by BAPB Inc.

2.2.2. Other Analyses Methods. The hydrocarbon pyrolysis analysis of the source rock was performed on a Rock-Eval 6 instrument. The $S_{1}$ peak was an adsorbed hydrocarbon, which was released in a helium atmosphere at $300^{\circ} \mathrm{C}$ for 3 minutes, representing the residual petroleum in the source rock. The pyrolysis hydrocarbon was those hydrocarbons released when the temperature rose to $600^{\circ} \mathrm{C}$ at a heating rate of $50^{\circ} \mathrm{C} / \mathrm{min}$ for 3 minutes.

The hydrocarbon content in the rock was obtained by chloroform extraction. A soxhlet extraction method was used, and the process involved wrapping about $150 \mathrm{~g}$ sample by filter paper extracted by chloroform, putting the samples in an extractor, adding dichloromethane and methanol (93:7, $\mathrm{v} / \mathrm{v}$ ) to the cycling bottles with a small piece of copper, heating at a constant bath temperature of $75^{\circ} \mathrm{C}$, and afterwards extracting 72 hours at circulating water cooling extraction.

The quantification of oil group components was gained by TLC-FID. The liquid hydrocarbons were dissolved in chloroform and boiled in a sintered silica column. The dissolved hydrocarbons were separated into saturates, aromatics, resin, and asphaltenes based on the different polarity and were identified by the flame ion detector. The mass percentage of each of the group components was calculated with the method of peak area normalization. The solvents utilized included hexane, dichloromethane, chloroform, and isopropanol.

Gas chromatographic analysis of the saturate was obtained by the Agilent 7890 gas chromatograph. The chromatographic column was HP-5MS $(30 \mathrm{~m} \times 0.25 \mathrm{~mm}$ $\times 0.25 \mu \mathrm{m})$. Helium was the carrier gas. The programmed heating procedures were set as follows: the initial temperature was $100^{\circ} \mathrm{C}$ and held for $5 \mathrm{~min}$. Then the temperature increased to $300^{\circ} \mathrm{C}$ with a heating rate of $4.0^{\circ} \mathrm{C} / \mathrm{min}$, detected by FID detector after heated for $15 \mathrm{~min}$.

\section{Results and Discussion}

3.1. Category of Petroleum Occurrence in Sedimentary Basins. There are three categories of petroleum occurrences. One remained in source rocks, the second is dispersed along the migration pathways, and the third is trapped in the structural or lithology-stratigraphic reservoirs. The third type of hydrocarbons is conventional oil and gas exploration target. However, under the conditions of high temperature in deep strata, the former two types of petroleum could also act as significant sources for gas accumulations when the secondary cracking happened. Zhao et al. $[4,5,12,18]$ discussed the concept of "relaying gas generation" model (gas generated from kerogen primary cracking followed by gas from petroleum secondary cracking) of the residual petroleum within the sources and the dispersed petroleum in reservoirs, indicating that both can become the main sources of deep gas.

3.1.1. Retained Petroleum in Source Rocks. In the traditional study of hydrocarbon source rock evaluation, free hydrocarbons (" $S_{1}$ ") or chloroform bitumen " $\mathrm{A}$ " of the rock pyrolysis parameters is approximately used as retained petroleum [20, $35]$. With the discovery of shale oil and gas, the evaluation accuracy of the hydrocarbon source rocks is further improved, and the quantitative evaluation of the residual petroleum is not satisfied with these two parameters. Volatile light components of free hydrocarbons (" $S_{1}$ ") cannot be detected during the experimental analysis, and at $300^{\circ} \mathrm{C}$, some of the heavy components cannot be completely desorbed and detected; therefore " $S_{1}$ " can only represent a portion of the residual petroleum [35]. Usually chloroform bitumen "A" mainly represents the medium-heavy components in residual petroleum. However, during the sample processing and analysis process, the light component would volatilize significantly. Thus, the components heavier than $\mathrm{C}_{13}$ can be detected using the conventional analysis, and the components lighter than $\mathrm{C}_{13}$ almost completely disappeared, so chloroform bitumen " $A$ " also only represents a part of the residual petroleum (Figure 1).

The generation of hydrocarbons generally experienced the process of kerogen-intermediate products-oil and gas. Behar et al. $[33,34]$ suggested that the intermediate products are mainly strong polar compounds which are rich in $\mathrm{N}$, $\mathrm{O}, \mathrm{S}$, and other heteroatoms. These compounds are soluble in n-pentane dichloromethane and other organic solvents. Among them, the compound which is soluble in n-pentane is roughly equivalent to pyrolysis " $S_{1}$ ", and for those which are soluble in methylene chloride, their contents are roughly comparable to the same as those of chloroform bitumen " $\mathrm{A}$ " (Figure 2). It can be seen that pyrolysis " $S_{1}$ " and chloroform bitumen " $A$ " mainly represent the intermediate product in 


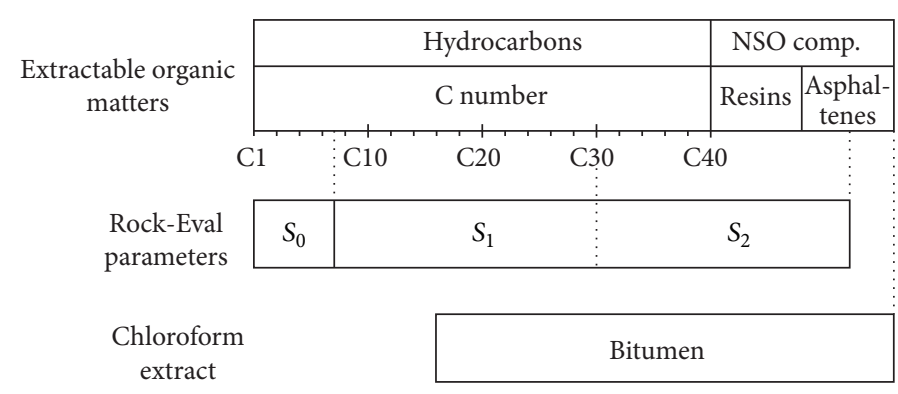

FIGURE 1: Relationship between pyrolysis parameters $S_{1}$, chloroform extracts, and residual petroleum (modified after [35]).



FIGURE 2: Relationships between Rock-Eval $S_{1}$, chloroform extracts, and soluble organic matters.

the conversion process from kerogen to oil, which is rich in NSO components. Some volatile hydrocarbon components may be largely dissipated and cannot be detected.

In order to achieve the accurate quantification of residual petroleum, it is necessary to restore the light components of chloroform bitumen "A". Zhu et al. [36] pointed out that the recovery coefficient of light hydrocarbons in chloroform bitumen "A" was between 1.2 and $1.6(R o=0.8 \% \sim 1.6 \%)$ when studying residual petroleum in source rocks from the Dongying Depression. After the light hydrocarbon recovery, the quantity of residual petroleum in the source rocks during the oil generation peak stage was about $50 \%$ of the total hydrocarbons generated.

A new method to recover the light components in the residual petroleum was provided in this paper. First, put the fresh rock sample as shown in Table 1 and some steel balls into a sealed container, then freeze them in liquid nitrogen, then let the steel balls grind rock samples in the container, and finally analyze the hydrocarbon component by online GC. For the oil generation peak samples (Xi 28 and PL 10 of the Sichuan Basin in Table 1), the light components in the residual petroleum inside the source at the oil generation peak stage accounted for about one-third of the total hydrocarbons, and this part would not be detectable using conventional methods. After the light components lost due to the analysis process are added back to the original components, it is found that the residual petroleum at the peak of oil production also accounts for about $50 \%$ of the total hydrocarbon production.

In addition, Zhang et al. [37] used the model of hydrocarbon generation and pressurization [38-40] to calculate the change of pressure within source rock. Results showed that oil and gas generation resulted in overpressure, and the maximum was more than $100 \mathrm{MPa}$ during the peak stage of oil generation if no hydrocarbon expelled. In order to keep the pressure unchanged, there should be about $25 \% \sim 50 \%$ of the hydrocarbon expelled.

As the maturity increases, the residual liquid hydrocarbons will be further cracked to form more light components and gaseous hydrocarbons, and the pressure in the source rocks will be further increased to promote more hydrocarbon expulsion outside the source rocks $[14,15,17]$. Thus, as the maturity increases, the content of residual petroleum in the source rocks will gradually decrease while the light component content will increase.

3.1.2. Petroleum outside the Source Rocks. The expelled hydrocarbons from source rocks might escape to the surface, or accumulate in traps, or disperse along the migration pathways. Due to the geological factors, such as the structural movement at the timing of reservoir formation, the reservoir conditions, and the later tectonic evolution, the proportions of the concentrated or dispersed liquid hydrocarbons are difficult to determine [52, 53]. Wang et al. [54] provided two methods to discuss the occurrence of the dispersed liquid hydrocarbons both in Sichuan Basin and in Tarim Basin. For example, the Sinian and Cambrian source rocks in the Sichuan Basin were at low mature stage (Ro value is about $0.7 \%$ ) in the early Silurian, and the GaoshitiMoxi structure had not yet been developed; thus the region cannot form large-scale oil and gas accumulations. The source rocks reached peak petroleum generation stages (Ro value increased from $0.7 \%$ to $2.0 \%$ ) at the Late PermianTriassic and formed paleo-oil reservoirs in the local reign and dispersed liquid hydrocarbons in the slope area [4]. The occurrence of the liquid hydrocarbons was partly controlled by the topographic gradient during the time of expulsion. When the gradient of slope areas exceeded $3^{\circ}$, expelled hydrocarbons tended to accumulate at paleohighs, forming significant hydrocarbon accumulations, while the abundance of hydrocarbons was lower and quite dispersed at the lower 
TABLE 3: Kinetics parameters for the cracking of individual organic compounds.

\begin{tabular}{lccc}
\hline Compound & Activation energy $(\mathrm{kcal} / \mathrm{mol})$ & Preexponential factor $\left(\mathrm{s}^{-1}\right)$ & Reference \\
\hline$n-\mathrm{C}_{14}$ & 67.6 & $7.20 E+18$ & {$[41]$} \\
$n-\mathrm{C}_{16}$ & 59.6 & $3.10 E+14$ & {$[42]$} \\
$n-\mathrm{C}_{16}$ & 74 & $3.00 E+19$ & {$[43]$} \\
$n-\mathrm{C}_{25}$ & 68.2 & $6.10 E+15$ & {$[44]$} \\
Tetralin & 58 & $3.50 E+12$ & {$[45]$} \\
Dodecylbenzene & 53.3 & $1.30 E+13$ & {$[46]$} \\
Pentadeylbenzene & 55.5 & $1.10 E+14$ & {$[47]$} \\
Butylbenzene & 52.9 & $1.10 E+12$ & {$[48]$} \\
Ethylbenzene & 62.3 & $4.70 E+13$ & {$[49]$} \\
3-Methylphenanthrene & 49 & $4.50 E+10$ & {$[50]$} \\
Dibenzothiophene & 59 & $1.90 E+11$ & {$[51]$} \\
\hline
\end{tabular}

gradient slopes and failed to form significant hydrocarbon accumulations.

3.2. Gas from Cracking of Liquid Hydrocarbons. The results of simulation experiments indicated that the stability of hydrocarbons is controlled by many factors. Among the intrinsic properties, chemical compositions are the primary ones. In order to elucidate the thermal stability of the liquid hydrocarbons with different compositions, the cracking kinetics of specific compounds were investigated.

3.2.1. Cracking Kinetic Parameters of Specific Compounds. The cracking of the alkanes is dominated by the C-C bond. The covalent bond first undergoes a homogeneous reaction under the action of thermal stress or the free radical initiators (such as $S$ and $R$ ) to generate free radicals and then triggers the free radical chain reaction $[55,56]$. The rate at the free radical initiation reaction (mainly the dissociation reaction of the $\mathrm{C}$ $\mathrm{C}$ bond) occurs as a rate step in the free radical chain reaction determining the rate of the alkane cracking reaction. The dissociation energy of $\mathrm{C}-\mathrm{C}$ bond increases with alkane carbon number decreasing [57]. That is to say, it is more difficult for alkanes with lower carbon number to crack. Actually, there exists linear relationship between the reaction rate constant $(k)$ and the carbon number $(\mathrm{i}): k_{i}\left[\mathrm{~s}^{-1}\right]=(2.3 i-15.6) \times 10^{-5}$ [58].

During the cracking process, cycloalkanes might experience side chain cleavage, aromatization, and cyclization of paraffin [59]. Cycloalkanes with side chains might subject to $\beta$-cleavage to transform methyl-cycloalkanes and straight chain alkanes when heated. Methyl-cycloalkanes would further undergo the ring splitting or aromatization to form more stably aromatic hydrocarbon. The labile aromatics, such as those with long side chain, would experience side chain cleavage [56]. However, for the relatively stable aromatics, mainly those with short side chain or the polycyclic aromatics, there are two possible pathways for further thermal evolution: transformation to cycloalkanes via hydrogenation or transformation to condensed aromatics via polymerization [60]. Since polycyclic aromatics are more thermally stable than monoaromatics or aromatics with free energy, it is more easily for aromatics to transform to condensed aromatics



FIGURE 3: Cracking curves of individual compounds under geological heating rate $\left(2^{\circ} \mathrm{C} / \mathrm{ma}\right)$.

via polymerization. Polymerization of aromatics (dehydrogenation) is usually accompanied by the pyrolysis of normal alkanes (hydrogenation), which is referred to as disproportionation. These disproportionation reactions could provide hydrogen sources for the hydrocarbon generation, and as a result, the relative proportion of light hydrocarbons and asphaltenes would increase.

The activation energy and preexponential factor for various compounds during cracking process are different greatly (Table 3). The activation energy and preexponential factor of n-alkane cracking are markedly higher than aromatics. Based on the molecular collision theory, with the same ambient temperature, the effective collision number of $n$-alkanes is markedly more than aromatics, of course with much higher energy barrier.

The cracking kinetics parameters of individual compounds could be deducted to geological conditions (Figure 3). 
It is obvious that the aromatics with no or short side chains have higher thermal stability than alkanes, whereas the aromatics with long side chains are of lower thermal stability. The reason is that the dissociation energy needed for $\beta$ cleavage of aromatics with long side chains is generally lower than C-C cleavage of alkanes. Thus, aromatics with long side chains are susceptible to side chain cleavage, transforming to more thermally stable methyl-aromatics and alkanes.

\subsubsection{Cracking Kinetics Parameters of Liquid Hydrocarbons} with Different Compositions. Differences in chemical composition and pyrolysis pathways will inevitably lead to different thermal stability during the liquid hydrocarbon cracking and it also determines the cracking temperature thresholds of hydrocarbons for the different compositions. The thermal stability of light components $\left(\mathrm{C}_{6-14}\right.$ saturates and aromatics) is obviously higher than that of heavy hydrocarbons $\left(\mathrm{C}_{14+}\right.$ saturates and aromatics) and heavy components (resin and asphaltenes). Tsuzuki et al. [31] divided the cracking of Sarukawa crude oil into seven components: gaseous hydrocarbons $\left(\mathrm{C}_{1-5}\right)$, light saturates $\left(\mathrm{C}_{6-14}\right.$ saturates $)$, light aromatics $\left(\mathrm{C}_{6-14}\right.$ aromatics $)$, heavy saturates $\left(\mathrm{C}_{15+}\right.$ saturates $)$, heavy concentrated aromatics, heavy nonconcentrated aromatics, and coke fractions

The oil and gas reservoir components can be divided into the following parts according to the difference of chemical compositions and thermal stability: (1) the lowest cracking activation energy of resin and asphaltenes $\left(\mathrm{C}_{14+}\right.$ NSO compounds) (50 55 kcal/mol); (2) intermediate activation energy of $\mathrm{C}_{14+}$ unstable aromatics (including alkyl side chain aromatic and naphthenic condensed aromatic components) and $\mathrm{C}_{14+}$ polycyclic condensed aromatics and methyl-aromatics; (3) high activation energy $(60-70 \mathrm{kcal} / \mathrm{mol})$ of $\mathrm{C}_{14+}$ saturates, light aromatics $\left(\mathrm{C}_{6-13}\right)$, and light saturates $\left(\mathrm{C}_{6-13}\right) ;(4)$ wet gas $\left(\mathrm{C}_{2-5}\right)$ with high stability (cracking activation energy greater than $70 \mathrm{kcal} / \mathrm{mol}$ ) and $\mathrm{CH}_{4}$ [31-33]. Different components have diverse thermal stabilities and cracking reaction paths and the secondary transformation process in the process of cracking. According to the cracking process of six different components, crude oil cracking could be divided into the following [31-33]:

$$
\begin{aligned}
& \mathrm{NSOs} \rightarrow a_{1} \mathrm{C}_{1-5}+a_{2} \mathrm{C}_{6-14} \mathrm{SAT}+a_{3} \mathrm{C}_{6-14} \mathrm{ARO}+ \\
& a_{4} \mathrm{C}_{14+} \mathrm{SAT}+a_{5} \mathrm{C}_{14+} \mathrm{ARO}-1+a_{6} \text { coke } \\
& \mathrm{C}_{14+} \mathrm{SAT} \rightarrow a_{7} \mathrm{C}_{1-5}+a_{8} \mathrm{C}_{6-14} \mathrm{SAT}+a_{9} \mathrm{C}_{14+} \mathrm{ARO}-2 \\
& \mathrm{C}_{14+} \mathrm{ARO}-1 \text { (with branch chain) } \rightarrow a_{10} \mathrm{C}_{1-5}+ \\
& a_{11} \mathrm{C}_{14+} \mathrm{ARO}-2 \\
& \mathrm{C}_{14+} \mathrm{ARO}-2 \text { (without branch chain) } \rightarrow \text { coke } \\
& \mathrm{C}_{6-14} \mathrm{SAT} \rightarrow a_{12} \mathrm{C}_{1-5}+a_{13} \text { coke } \\
& \mathrm{C}_{6-14} \mathrm{ARO} \rightarrow a_{14} \mathrm{C}_{1-5}+a_{15} \text { coke }
\end{aligned}
$$

The total amount of crude oil $c_{(\text {oil })}=\sum x_{i} c_{i}=$ $x_{1} c_{1}+x_{2} c_{2}+\cdots+x_{n} c_{n}$. The total rate of cracking of crude oil $k_{(\mathrm{oil})}=\sum x_{i} k_{i}=x_{1} k_{1}+x_{2} k_{2}+\cdots+x_{n} k_{n}$; that is, $k_{i}=A_{i} \exp \left(-E a_{i} / R T\right)$. The kinetic parameters of crude oil cracking are matched with $A \exp (-E a / R T)=$ $\sum x_{i} A_{i} \exp \left(-E a_{i} / R T\right)$.

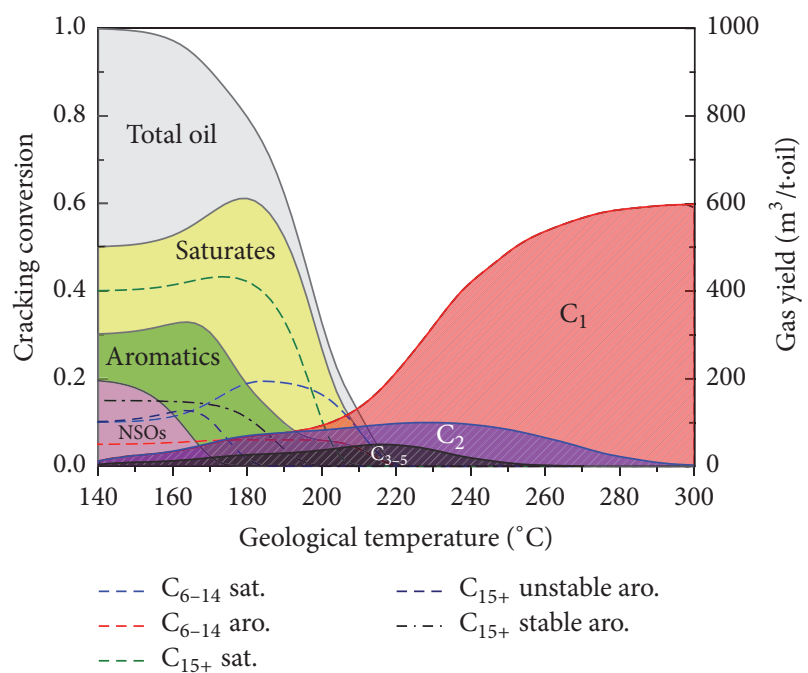

FIGURE 4: Gas generation model of crude oil and its components (heating rate $2^{\circ} \mathrm{C} / \mathrm{ma}$ ).

Among them, $x_{i}, c_{i}, k_{i}, A_{i}$, and $E_{a i}$ represent the relative content, the absolute amount, the rate constant, the preexponential factor, and the activation energy of the cracking reaction of the component, respectively. $X_{i}(i=1-6)$ represent $\mathrm{C}_{6-14}$ saturates, $\mathrm{C}_{14+}$ saturates, $\mathrm{C}_{6-14}$ aromatics, $\mathrm{C}_{14+}$ stabilized aromatics (polycyclic aromatics), $\mathrm{C}_{14+}$ unstable aromatics (including long chain), and nonhydrocarbon pitch (NSOs); $\sum x i=1$.

By geological extrapolation based on the conversion coefficient (ai) and kinetic parameters obtained by previous experimental works [31,33], a cracking model for crude oil with specific compositions can be established as indicated in Figure 4.

Under the geological conditions (heating rate $2^{\circ} \mathrm{C} / \mathrm{Ma}$ ), resin and asphaltenes began to crack at $135^{\circ} \mathrm{C}$ and cracked completely at about $170^{\circ} \mathrm{C}$. Aromatics began to crack at about $160^{\circ} \mathrm{C}$ and cracked completely at $220^{\circ} \mathrm{C}$. Aromatics started to crack at about $160^{\circ} \mathrm{C}$ and completely finished at $220^{\circ} \mathrm{C}$. The starting cracking temperature of $\mathrm{C}_{15+}$ unstable aromatics was $160^{\circ} \mathrm{C}, \mathrm{C}_{15+}$ stable aromatics was over $170^{\circ} \mathrm{C}$, and $\mathrm{C}_{6-14}$ aromatics started over $200^{\circ} \mathrm{C}$. Saturates were the most stable components, with peak cracking temperature exceeding $180^{\circ} \mathrm{C}$, and completely cracked at $220^{\circ} \mathrm{C}$. The $\mathrm{C}_{15+}$ saturates started to crack at $175^{\circ} \mathrm{C}$ and the $\mathrm{C}_{6 \sim 14}$ saturates began to crack at $185^{\circ} \mathrm{C}$. When the temperature exceeded $220^{\circ} \mathrm{C}$ wet gas components $\left(\mathrm{C}_{3 \sim 5}\right)$ began to crack.

3.2.3. Amount of Cracked Gas from Liquid Hydrocarbons with Various Compositions. The gas generation potential of the liquid hydrocarbons is influenced by the $\mathrm{H} / \mathrm{C}$ atomic ratio and thermal reaction pathways. The highest yield of gaseous hydrocarbon production of per unit waxy oil or light oil could reach $800 \mathrm{ml} / \mathrm{g}$ (with mass production of $600 \mathrm{mg} / \mathrm{g}$ ), obviously higher than normal oil and heavy oils, with high quantities of resins and asphaltenes. The maximum hydrocarbon yield of normal oil and heavy oil is $680 \mathrm{ml} / \mathrm{g}$ and $599 \mathrm{ml} / \mathrm{g}$, and the peak mass production is $500 \mathrm{mg} / \mathrm{g}$ and $450 \mathrm{mg} / \mathrm{g}$, respectively (Figure 5). 

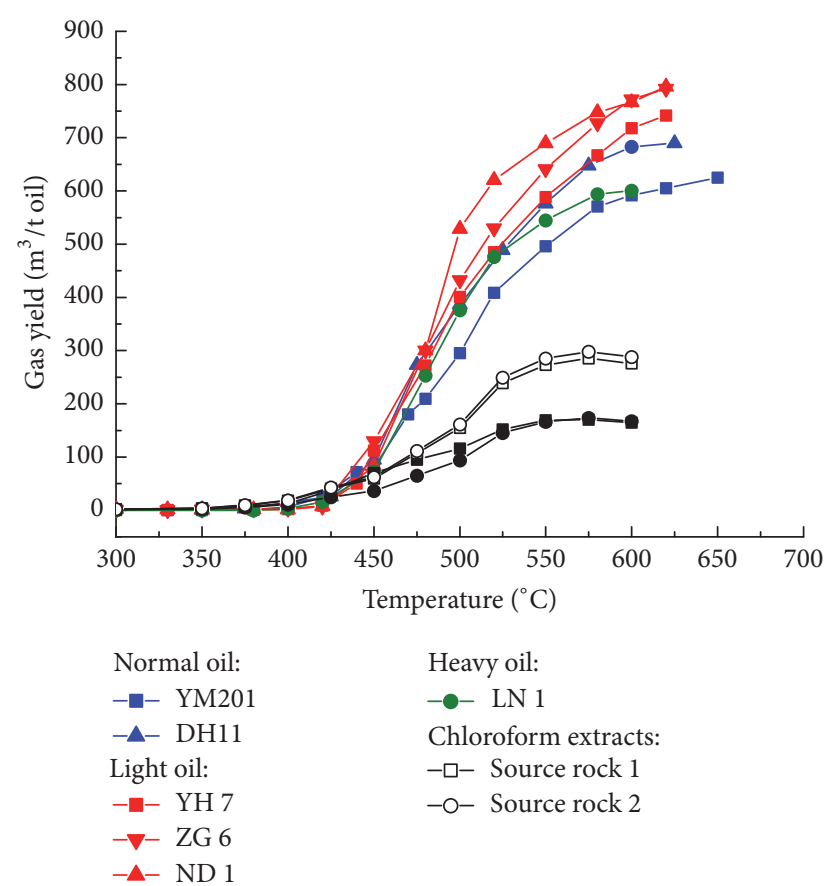

FIGURE 5: The volume production of gaseous hydrocarbons from liquid hydrocarbons with different compositions (heating rate: $\left.20^{\circ} \mathrm{C} / \mathrm{min}, 50 \mathrm{MPa}\right)$.

The maximum gas production has a positive relationship with saturates and negative relationship with heavy components. It is indicated that saturates with high hydrogen percentage (especially paraffin) generally experience C-C bond cracking to form micromolecule hydrocarbon and gaseous hydrocarbons during pyrolysis process. For resins and asphaltenes, gaseous hydrocarbon mainly originated from the cracking of branched chain structure and and finally aromatic ring condensed to form heavy asphaltenes.

The correlation mathematical relationship of gas production of secondary cracking and group compositions could be expressed as follows:

Gas production:

$$
\begin{aligned}
M(\mathrm{mg} / \mathrm{g} \text { oil })= & 95.2 \times\left[\frac{\text { saturated fraction }}{\text { aromatic fraction }}\right]-564.9 \\
& \times(\text { polar fraction percentage }) \\
& +a \text { (constant })
\end{aligned}
$$

Kinetic characterizations of gaseous hydrocarbons are different for liquid residual in source rocks and that of outside sources, which is mainly caused by hydrocarbon expulsion, resulting in a higher proportion of heavy fractions in the residuals hydrocarbons retained in the source rocks. Shale and argillaceous source rocks usually contain clay minerals with catalytic capabilities. Based on the group composition of residual petroleum retained in source rocks and gas production calculation, maximum gas production of residual hydrocarbon in source rocks and crude oil outside source could be obtained, averagely $500 \mathrm{ml} / \mathrm{g}$ and $690 \mathrm{ml} / \mathrm{g}$.

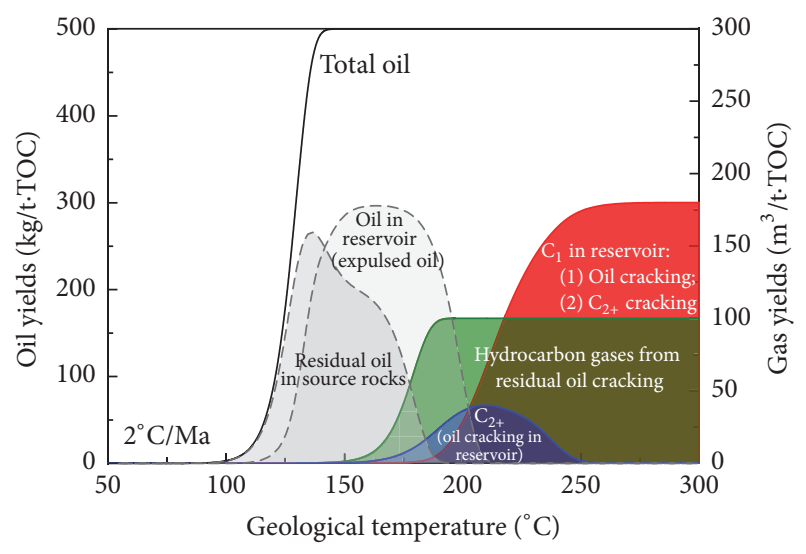

FIGURE 6: Gas generation model for the cracking of residual oil in Type-II source rocks and expelled crude oil in reservoir under geological conditions (heating rate: $2^{\circ} \mathrm{C} / \mathrm{Ma}$ ). The conversion of the generation and cracking of oil and gas were obtained by kinetic extrapolation based on their kinetic parameters, wherein the kinetic parameters $\left(E a\right.$ and $\left.A_{f}\right)$ applied in this model for oil generation were $51.4 \mathrm{kcal} / \mathrm{mol}$ and $8.14 E+13 \mathrm{~s}^{-1}$ [9], for oil cracking in reservoir were $59.8 \mathrm{kcal} / \mathrm{mol}$ and $2.13 E+13 \mathrm{~s}^{-1}$ [2], and for residual oil cracking in source were $56.1 \mathrm{kcal} / \mathrm{mol}$ and $1.0 E+13 \mathrm{~s}^{-1}$ [61].

Previous studies revealed that the average activation energy of the residual oil cracking is $234.1 \mathrm{~kJ} / \mathrm{mol}$, which is significantly lower than the liquid hydrocarbon cracking outside sources $[2,3]$. This is mainly due to the significantly high levels of residual heavy hydrocarbon components and the possible catalytic effect of clay minerals in the source rocks.

Based on the abroad research results from hydrocarbon generation, evolution, and the trend of overpressure in the sources, a gas general model from the cracking of residual oil (in source) and expelled oil (in reservoir or out of source) derived from Type-II kerogen can be established (Figure 6). If we supposed the maximum oil potential for the Type-II kerogen as $500 \mathrm{mg} / \mathrm{g}$ TOC, the amount of the gas generation from the cracking oil or liquid hydrocarbons with different occurrence states can be evaluated. At the stage of oil generation peak (about $135^{\circ} \mathrm{C}$ ), the amounts of the liquid hydrocarbons from in and out the sources account for about $50 \%$, respectively. Due to the fractionation during expulsion, the components of two states of oil may differ a lot. For example, the liquid hydrocarbons trapped inside the sources contain heteroatom compounds of $\mathrm{N}, \mathrm{O}$, and $\mathrm{S}$, and the cracked gas production from the liquid hydrocarbons inside the sources is less than those from the liquid hydrocarbons outside the sources.

The liquid hydrocarbons inside the sources began to crack at $135^{\circ} \mathrm{C}$, cracked rapidly at $170^{\circ} \mathrm{C}$, and terminated at $200^{\circ} \mathrm{C}$. However, the cracking of hydrocarbons outside the sources started at $175^{\circ} \mathrm{C}$ and exhausted at $220^{\circ} \mathrm{C}$.

At the early stage of the liquid hydrocarbon cracking, the content of the wet gas is higher. With higher strata temperature, the content of the methane gradually increases, until the content of methane exceeds the wet gas, and then the wet gas starts to crack at $220^{\circ} \mathrm{C}$. 


\subsection{Potential and Significance of Secondary Cracking Gas}

3.3.1. Potential of Cracked Gas from Residual Oil in Source Rocks. Large amount of thermally cracked gas can become an important gas source kitchen for shale gas, which is formed in the mature/overmature stages by dispersed liquid hydrocarbons inside the sources [53, 62]. Before 2000, many experts thought that there is no exploration potential in the area where the source rocks are highly mature to overmature, because the hydrocarbon generation is thought to have been exhausted at those maturities [20]. In fact, there are still a considerable number of liquid hydrocarbons trapped in the source rocks after hydrocarbon source rocks enter the "oil window" stage. Based on the simulation experiment of hydrocarbon generation and expulsion and dynamics analysis of gas generation, Zhao et al. $[12,18]$ concluded that (1) large amount of liquid hydrocarbons discharged from the source rocks occurred in the stage of "oil window," with Ro values range within $0.6 \% \sim 1.2 \%$, the expulsion efficiency of the source rocks is generally $40 \% \sim 60 \%$, and the oil shale has the highest hydrocarbon efficiency (80\%); (2) kerogen degrades in the early stage of maturity/high maturity, and Ro value ranges within $1.2 \% \sim 1.6 \%$, and the gas cracking from the hydrocarbons entrapped in source rocks happen in the stage of high maturity/overmaturity with a $R o$ value over $1.6 \%$. The Ro value of the main gas generation is $1.5 \%$ 3.2\%. Although the gas generated from the liquid hydrocarbons is later than those degraded from the kerogen, the amount of the gas from the former is $2 \sim 4$ times more than the gas from the latter. Therefore, the quantity of liquid hydrocarbons trapped in the source rocks can be considerable, and the amount of natural gas formed in the high to overmaturity stage is much larger than the amount of natural gas formed by the degradation of kerogen. Therefore it is a kind of late accumulation natural gas and becomes an effective gas source kitchen.

The black shale in the Silurian Longmaxi Formation in the Sichuan Basin is a high quality source rock with high organic matter abundance and TOC in the lower black shale section is between $3 \%$ and $6 \%$, average $3.5 \%$. The maturity of the organic matter is high. The equivalent vitrinite reflectance $(R o)$ is between $2.0 \%$ and $4.0 \%$, in the mature stage. In recent years, the black shale which is similar to the Longmaxi Formation has been found in several shale gas fields such as Fuling, Changning, and Weiyuan. The methane and ethane carbon isotopes of the shale gas are significantly reversed $[62,63]$. The main reason for this reversal is the mixing of gas cracked from the liquid hydrocarbons in the high mature/overmature stages of the shale and the gas degraded from the kerogen in the early stage [63, 64], which is also supported by widely distributed solid asphaltenes in shale [1]. The thermogenic shale gas is a kind of unconventional gas mainly distributing in the organic-rich shale with a thickness greater than $15 \mathrm{~m}$ and Ro value within 1.1\% 3.0\%. Higher or lower maturity values do not appear to be beneficial to the formation and preservation of cracked gas. So the discovery of the thermogenic shale gas is a strong evidence of the retention of hydrocarbons in situ.
3.3.2. Contribution of Liquid Hydrocarbons outside Source Rocks to the Gas Accumulations. The secondary cracking of liquid hydrocarbon was the main source of most marine deep gas fields. Lower Paleozoic marine source rocks of three major Chinese marine basins are all at mature/overmature stages (Ro value ranges from $2.5 \%$ to $3.5 \%$ ). It is commonly reported that discovery of large gas fields from gas cracked liquid hydrocarbon accumulation (paleo-oil accumulations) under high temperature $[52,53]$. Asphaltene is a secondary cracking product from the liquid hydrocarbons, and its abundance could be used as an evidence for oil secondary cracking. Generally, in the high parts of the slope with steep strata angle (the higher area of the paleogeography), liquid hydrocarbons could form large-scale oil accumulations. This kind of paleo-oil reservoirs usually has high content of asphaltenes. These accumulated liquid hydrocarbons are mainly controlled by paleostructures. Paleouplift is a favorable area for the liquid hydrocarbons to accumulate. The concentrated liquid hydrocarbon is mainly controlled by paleo-strata temperature. The Paleozoic paleouplifts of the Sichuan Basin are well developed and the paleo-geothermal gradient temperature was high; therefore, the scales of the cracking gas resources from liquid hydrocarbons may be tremendous.

The dispersed liquid hydrocarbons outside the sources also contribute to the formation of the conventional gas accumulations. The tectonic patterns of the Sichuan and Tarim basins in China are mostly in the form of "big uplift and big depression." The distribution of oil and gas is mainly controlled by these large paleouplifts and relatively stable large-scale paleoslopes. Based on the accumulation of the liquid hydrocarbons, the paleo-terrain slope of the reservoirs is an important controlling factor for the enrichment degree and the pattern of the liquid hydrocarbons. In the slope area with low strata angel, the differentiation action of the liquid hydrocarbons is small.

In previous studies $[4,54]$, "five-step-method" has been used to calculate the gas potential of the Sichuan Basin. The liquid hydrocarbons retained in source rocks, dispersed along migration pathways, and accumulated in paleostructures were cracked into gas of 886,588 , and 298 trillion cubic meters, respectively. Based on the factors such as tectonic movement, accumulation and preservation conditions in the main gas generation period and the later period, the amount of effective resources is $0.89,1.76$, and 1.49 trillion cubic meters, respectively. The contribution ratio of the three categories oil to gas resource is $21 \%, 43 \%$, and $36 \%$, respectively. Therefore the liquid hydrocarbons can be cracked and formed large gas accumulations in the late stage, contributing to the deep gas resources.

Because of the contribution of the aggregated paleo-oil reservoirs and dispersed liquid hydrocarbons, the largest single gas field in the Sinian and Cambrian old formations of the Gaoshiti-Moxi area has been formed in the Sichuan Basin, which has been explored for nearly 100 years [52, 53]. The proven natural gas reserves in the Longwangmiao Formation of the Moxi area reach $440.38 \times 10^{9} \mathrm{~m}^{3}$, and controlled reserves in the fourth section of the Sinian Dengying 
Formation amount to $204.29 \times 10^{9} \mathrm{~m}^{3}$, illustrating great potentials for deep gas exploration.

The production evidence declare that the high source rock maturity would not retain or maintain gas contents in reservoir, although at some locations $\% R o$ values greater than $3 \%$ to $3.5 \%$ Ro are found in both China and North America. It is uncertain whether this is due to loss of containment of the gas or chemical alteration. This is a risk factor for commercial shale gas exploration and needs further studies.

\section{Conclusions}

There are three categories of petroleum occurrence, that is, residues in the source rocks, retained along migration pathways and trapped in paleoreservoirs. All of them are important sources for deep gas accumulations. At the peak stage of oil generation, the amount of hydrocarbons retained in the source rock is about $50 \%$.

The pyrolysis kinetic parameters of different types of liquid hydrocarbons differ greatly, depending mainly on their compositions. Saturates are the most stable components, requiring high pyrolysis activation energy and high pyrolysis temperature, while the pyrolysis of bitumen only needs low temperature and the activation energy is low. At mature to overmature stages, the required cracking temperature of residual petroleum in source rocks is lower than that of the migrated-out hydrocarbons. The cracked gas generations yield from the residual petroleum in source rocks generally lower that of the migrated-out hydrocarbons.

The cracking of deeply buried liquid hydrocarbons becomes an important source to different types of gas accumulations. The cracking of residual petroleum in source rocks not only becomes the sole source for shale gas but also contributes to the conventional deep natural gas accumulations when expelled. The dispersed liquid hydrocarbons along migration pathways or elsewhere can also be cracked to form natural gas under high temperature and accumulated under suitable geological conditions. The paleo-oil accumulations become the main source for conventional gas accumulations after cracking. The trapped paleo-oil reservoir and the dispersed liquid hydrocarbons along migration pathways can jointly form giant deep natural gas accumulations.

\section{Conflicts of Interest}

The authors declare that there are no conflicts of interest regarding the publication of this paper.

\section{References}

[1] J. Dai, C. Zou, S. Liao et al., "Geochemistry of the extremely high thermal maturity Longmaxi shale gas, southern Sichuan Basin," Organic Geochemistry, vol. 74, pp. 3-12, 2014.

[2] K. He, S. C. Zhang, X. M. Wang, and J. K. Mi, "Research on the kinetics and controlling factor for oil cracking," Natural Gas Geoscience, vol. 22, pp. 211-218, 2011.

[3] S. C. Zhang, G. Y. Hu, J. K. Mi et al., "Time-limt and yield of natural gas generation from different origins and their effect on forecast of deep oil and gas resources," Acta Petrolei Sinica, vol. 34, no. S1, pp. 41-50, 2013.

[4] W. Zhao, S. Hu, W. Liu, T. Wang, and H. Jiang, "The multi-staged "golden zones" of hydrocarbon exploration in superimposed petroliferous basins of onshore China and its significance," Petroleum Exploration and Development, vol. 42, no. 1, pp. 1-12, 2015.

[5] W. Zhao, Z. Wang, D. Wang, J. Li, Y. Li, and G. Hu, "Contribution and significance of dispersed liquid hydrocarbons to reservoir formation," Petroleum Exploration and Development, vol. 42, no. 4, pp. 439-453, 2015.

[6] A. S. Pepper and T. A. Dodd, "Simple kinetic models of petroleum formation. Part II: oil-gas cracking," Marine and Petroleum Geology, vol. 12, no. 3, pp. 321-340, 1995.

[7] H. J. Schenk, R. Di Primio, and B. Horsfield, "The conversion of oil into gas in petroleum reservoirs. Part 1: Comparative kinetic investigation of gas generation from crude oils of lacustrine, marine and fluviodeltaic origin by programmed-temperature closed-system pyrolysis," Organic Geochemistry, vol. 26, no. 78, pp. 467-481, 1997.

[8] G. P. Cooles, A. S. Mackenzie, and T. M. Quigley, "Calculation of petroleum masses generated and expelled from source rocks," Organic Geochemistry, vol. 10, no. 1-3, pp. 235-245, 1986.

[9] A.S. Pepper and P. J. Corvi, "Simple kinetic models of petroleum formation. Part I: oil and gas generation from kerogen," Marine and Petroleum Geology, vol. 12, no. 3, pp. 291-319, 1995.

[10] D. Leythaeuser, M. Radke, and R. G. Schaefer, "Efficiency of petroleum expulsion from shale source rocks," Nature, vol. 311, no. 5988, pp. 745-748, 1984.

[11] U. Ritter, "Solubility of petroleum compounds in kerogen: Implications for petroleum expulsion," Organic Geochemistry, vol. 34, no. 3, pp. 319-326, 2003.

[12] Z. W. Zhao, Y. Z. Wang, and C. S. Zhang, "Successive generation of natural gas from organic materials and its significance in future exploration," Petroleum Exploration and Development, vol. 32, no. 2, pp. 1-7, 2005.

[13] D. Ertas, S. R. Kelemen, and T. C. Halsey, "Petroleum expulsion part 1. Theory of kerogen swelling in multicomponent solvents," Energy and Fuels, vol. 20, no. 1, pp. 295-300, 2006.

[14] S. R. Kelemen, C. C. Walters, D. Ertas, H. Freund, and D. J. Curry, "Petroleum expulsion part 3. A model of chemically driven fractionation during expulsion of petroleum from kerogen," Energy and Fuels, vol. 20, no. 1, pp. 309-319, 2006.

[15] H. Freund, C. C. Walters, S. R. Kelemen et al., "Predicting oil and gas compositional yields via chemical structure-chemical yield modeling (CS-CYM): Part 1 - Concepts and implementation," Organic Geochemistry, vol. 38, no. 2, pp. 288-305, 2007.

[16] D. M. Jarvie, R. J. Hill, T. E. Ruble, and R. M. Pollastro, "Unconventional shale-gas systems: the Mississippian Barnett Shale of north-central Texas as one model for thermogenic shale-gas assessment," AAPG Bulletin, vol. 91, no. 4, pp. 475499, 2007.

[17] J. G. Stainforth, "Practical kinetic modeling of petroleum generation and expulsion," Marine and Petroleum Geology, vol. 26, no. 4, pp. 552-572, 2009.

[18] W. Zhao, Z. Wang, H. Wang, Y. Li, G. Hu, and C. Zhao, "Further discussion on the connotation and significance of the natural gas relaying generation model from organic matter," Petroleum Exploration and Development, vol. 38, no. 2, pp. 129-135, 2011.

[19] C. C. Walters, H. Freund, S. R. Kelemen, P. Peczak, and D. J. Curry, "Predicting oil and gas compositional yields via 
chemical structure-chemical yield modeling (CS-CYM): Part 2 - Application under laboratory and geologic conditions," Organic Geochemistry, vol. 38, no. 2, pp. 306-322, 2007.

[20] K. A. Kvenvolden, "Petroleum geochemistry and geology," Organic Geochemistry, vol. 24, no. 1, pp. 109-110, 1996.

[21] D. W. Waples, "The kinetics of in-reservoir oil destruction and gas formation: Constraints from experimental and empirical data, and from thermodynamics," Organic Geochemistry, vol. 31, no. 6, pp. 553-575, 2000.

[22] A. K. Burnham and R. L. Braun, "Development of a detailed model of petroleum formation, destruction, and expulsion from lacustrine and marine source rocks," Organic Geochemistry, vol. 16, no. 1-3, pp. 27-39, 1990.

[23] B. Horsfield, H. J. Schenk, N. Mills, and D. H. Welte, "An investigation of the in-reservoir conversion of oil to gas: compositional and kinetic findings from closed-system programmedtemperature pyrolysis," Organic Geochemistry, vol. 19, no. 1-3, pp. 191-204, 1992.

[24] R. I. McNeil, "Thermal stability of hydrocarbons: Laboratory criteria and field examples," Energy \& Fuels, vol. 10, no. 2, pp. 60-67, 1996.

[25] F. Dominé, D. Dessort, and O. Brévart, "Towards a new method of geochemical kinetic modelling: Implications for the stability of crude oils," Organic Geochemistry, vol. 28, no. 9-10, pp. 597$612,1998$.

[26] V. Dieckmann, H. J. Schenk, B. Horsfield, and D. H. Welte, "Kinetics of petroleum generation and cracking by programmed-temperature closed-system pyrolysis of Toarcian Shales," Fuel, vol. 77, no. 1-2, pp. 23-31, 1998.

[27] R. J. Hill, Y. Tang, and I. R. Kaplan, "Insights into oil cracking based on laboratory experiments," Organic Geochemistry, vol. 34, no. 12, pp. 1651-1672, 2003.

[28] W. Zhao, Z. Wang, S. Zhang, H. Wang, and Y. Wang, "Oil cracking: An important way for highly efficient generation of gas from marine source rock kitchen," Chinese Science Bulletin, vol. 50, no. 22, pp. 2628-2635, 2005.

[29] H. Tian, X. Xiao, L. Yang et al., "Pyrolysis of oil at high temperatures: Gas potentials, chemical and carbon isotopic signatures," Chinese Science Bulletin, vol. 54, no. 7, pp. 1217-1224, 2009.

[30] V. Dieckmann, P. G. Caccialanza, and R. Galimberti, "Evaluating the timing of oil expulsion: About the inverse behaviour of light hydrocarbons and oil asphaltene kinetics," Organic Geochemistry, vol. 33, no. 12, pp. 1501-1513, 2002.

[31] N. Tsuzuki, N. Takeda, M. Suzuki, and K. Yokoi, “The kinetic modeling of oil cracking by hydrothermal pyrolysis experiments," International Journal of Coal Geology, vol. 39, no. 1-3, pp. 227-250, 1999.

[32] M. Vandenbroucke, F. Behar, and J. L. Rudkiewicz, "Kinetic modelling of petroleum formation and cracking: Implications from the high pressure/high temperature Elgin Field (UK, North Sea)," Organic Geochemistry, vol. 30, no. 9, pp. 1105-1125, 1999.

[33] F. Behar, F. Lorant, and L. Mazeas, "Elaboration of a new compositional kinetic schema for oil cracking," Organic Geochemistry, vol. 39, no. 6, pp. 764-782, 2008.

[34] F. Behar, S. Roy, and D. Jarvie, "Artificial maturation of a Type I kerogen in closed system: Mass balance and kinetic modelling," Organic Geochemistry, vol. 41, no. 11, pp. 1235-1247, 2010.

[35] M. Bordenave, Applied Petroleum Geochemistry, Technip, Paris, 1993.
[36] F. R. Zhu, Y. L. Zhang, and Y. Li, "Quantitative evaluation residual liquid hydrocarbons in shale," Acta Petrolei Sinica, vol. 36, no. 1, pp. 13-18, 2015.

[37] B. Zhang, J. Hu, and J. Yang, "Controlling effect of source rocks on the occurrence of tight oil - taking the Da'anzhai reservoir of Sichuan Basin as an example," Bulletin of Mineralogy, Petrology and Geochemistry, vol. 34, no. 1, pp. 45-54, 2015.

[38] X. Guo, S. He, K. Liu, G. Song, X. Wang, and Z. Shi, "Oil generation as the dominant overpressure mechanism in the Cenozoic Dongying depression, Bohai Bay Basin, China," AAPG Bulletin, vol. 94, no. 12, pp. 1859-1881, 2010.

[39] X. Guo, S. He, K. Liu, and L. Zheng, "Quantitative estimation of overpressure caused by oil generation in petroliferous basins," Organic Geochemistry, vol. 42, no. 11, pp. 1343-1350, 2011.

[40] X. W. Guo, K. Y. Liu, S. He, Z. Yang, and T. T. Dong, "Quantitative estimation of overpressure caused by gas generation and application to the Baiyun Depression in the Pearl River Mouth Basin, South China Sea," Geofluids, vol. 16, no. 1, pp. 129-148, 2016.

[41] C. Song, W.-C. Lai, and H. H. Schobert, "Condensed-phase pyrolysis of n-tetradecane at elevated pressures for long duration. Product distribution and reaction mechanisms," Industrial \& Engineering Chemistry Research, vol. 33, no. 3, pp. 534-547, 1994.

[42] T. J. Ford, "Liquid-phase thermal decomposition of hexadecane: Reaction mechanisms," Industrial and Engineering Chemistry Fundamentals, vol. 25, no. 2, pp. 240-243, 1986.

[43] K. J. Jackśon, A. K. Burnham, R. L. Braun, and K. G. Knauss, "Temperature and pressure dependence of n-hexadecane cracking," Organic Geochemistry, vol. 23, no. 10, pp. 941-953, 1995.

[44] F. Behar and M. Vandenbroucke, "Experimental determination of the rate constants of the n-C25 thermal cracking at 120, 400, and 800 bar: Implications for high-pressure/high-temperature prospects," Energy and Fuels, vol. 10, no. 4, pp. 932-940, 1996.

[45] J. Yu and S. Eser, "Thermal decomposition of jet fuel model compounds under near-critical and supercritical conditions. 2. Decalin and tetralin," Industrial and Engineering Chemistry Research, vol. 37, no. 12, pp. 4601-4608, 1998.

[46] F. Behar, F. Lorant, H. Budzinski, and E. Desavis, "Thermal stability of alkylaromatics in natural systems: Kinetics of thermal decomposition of dodecylbenzene," Energy and Fuels, vol. 16, no. 4, pp. 831-841, 2002.

[47] P. E. Savage and M. T. Klein, "Asphaltene reaction pathways. 2. Pyrolysis of n-pentadecylbenzene," Industrial and Engineering Chemistry Research, vol. 26, no. 3, pp. 488-494, 1987.

[48] H. Freund and W. N. Olmstead, "Detailed chemical kinetic modeling of butylbenzene pyrolysis," International Journal of Chemical Kinetics, vol. 21, no. 7, pp. 561-574, 1989.

[49] S. B. Domke, R. F. Pogue, F. J. R. Van Neer, and C. M. Smith, "Investigation of the kinetics of ethylbenzene pyrolysis using a temperature-scanning reactor," Industrial and Engineering Chemistry Research, vol. 40, no. 25, pp. 5878-5884, 2001.

[50] F. Behar, H. Budzinski, M. Vandenbroucke, and Y. Tang, "Methane generation from oil cracking: Kinetics of 9methylphenanthrene cracking and comparison with other pure compounds and oil fractions," Energy and Fuels, vol. 13, no. 2, pp. 471-481, 1999.

[51] C. Dartiguelongue, F. Behar, H. Budzinski, G. Scacchi, and P. M. Marquaire, "Thermal stability of dibenzothiophene in closed system pyrolysis: Experimental study and kinetic modelling," Organic Geochemistry, vol. 37, no. 1, pp. 98-116, 2006. 
[52] J. Du, C. Zou, C. Xu et al., "Theoretical and technical innovations in strategic discovery of a giant gas field in Cambrian Longwangmiao Formation of central Sichuan paleo-uplift, Sichuan Basin," Shiyou Kantan Yu Kaifa/Petroleum Exploration and Development, vol. 41, no. 3, pp. 268-277, 2014.

[53] C. Zou, J. Du, C. Xu et al., "Formation, distribution, resource potential and discovery of the sinian-cambrian giant gas field, sichuan basin, SW China," Petroleum Exploration and Development, vol. 41, no. 3, pp. 278-293, 2014.

[54] Y. Z. Wang, Z. W. Zhao, and L. D. Wang, "Quantitative assessment of pyrolysis gas generated by dispersed liquid hydrocarbon," Acta Geologica Sinica, vol. 90, no. 1, pp. 68-79, 2016.

[55] Y. V. Kissin, "Catagenesis and composition of petroleum: Origin of n-alkanes and isoalkanes in petroleum crudes," Geochimica et Cosmochimica Acta, vol. 51, no. 9, pp. 2445-2457, 1987.

[56] M. L. Poutsma, "Fundamental reactions of free radicals relevant to pyrolysis reactions," Journal of Analytical and Applied Pyrolysis, vol. 54, no. 1, pp. 5-35, 2000.

[57] Y. Tang, J. K. Perry, P. D. Jenden, and M. Schoell, "Mathematical modeling of stable carbon isotope ratios in natural gases," Geochimica et Cosmochimica Acta, vol. 64, no. 15, pp. 2673-2687, 2000.

[58] H. H. Voge and G. M. Good, "Thermal cracking of higher paraffins," Journal of the American Chemical Society, vol. 71, no. 2, pp. 593-597, 1949.

[59] P. Castaño, J. M. Arandes, M. Olazar, J. Bilbao, B. Pawelec, and U. Sedrán, "Effect of hydrogen on the cracking mechanisms of cycloalkanes over zeolites," Catalysis Today, vol. 150, no. 3-4, pp. 363-367, 2010.

[60] L. Fusetti, F. Behar, R. Bounaceur, P.-M. Marquaire, K. Grice, and S. Derenne, "New insights into secondary gas generation from the thermal cracking of oil: Methylated monoaromatics. A kinetic approach using 1,2,4-trimethylbenzene. Part I: A mechanistic kinetic model," Organic Geochemistry, vol. 41, no. 2, pp. 146-167, 2010.

[61] K. He, S. Zhang, X. Wang, J. Mi, R. Mao, and G. Hu, “Effect of gas generation from in-situ cracking of residual bitumen in source on hydrocarbon generation from organic matter," Shiyou Xuebao/Acta Petrolei Sinica, vol. 34, no. 1, pp. 57-64, 2013.

[62] R. Yang, S. He, Q. Hu, D. Hu, and J. Yi, “Geochemical characteristics and origin of natural gas from Wufeng-Longmaxi shales of the Fuling gas field, Sichuan Basin (China)," International Journal of Coal Geology, vol. 171, pp. 1-11, 2017.

[63] S. Zhang, K. He, G. Hu et al., "Unique chemical and isotopic characteristics and origins of natural gases in the Paleozoic marine formations in the Sichuan Basin, SW China: Isotope fractionation of deep and high mature carbonate reservoir gases," Marine and Petroleum Geology, 2016.

[64] X. Xia, J. Chen, R. Braun, and Y. Tang, "Isotopic reversals with respect to maturity trends due to mixing of primary and secondary products in source rocks," Chemical Geology, vol. 339, pp. 205-212, 2013. 

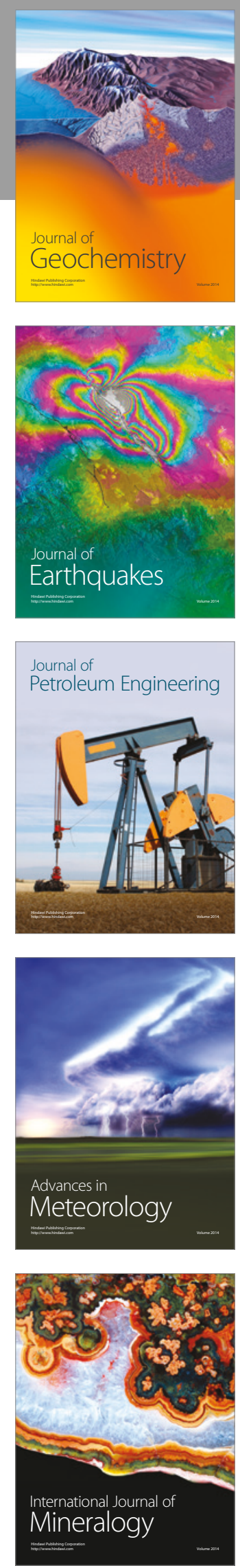
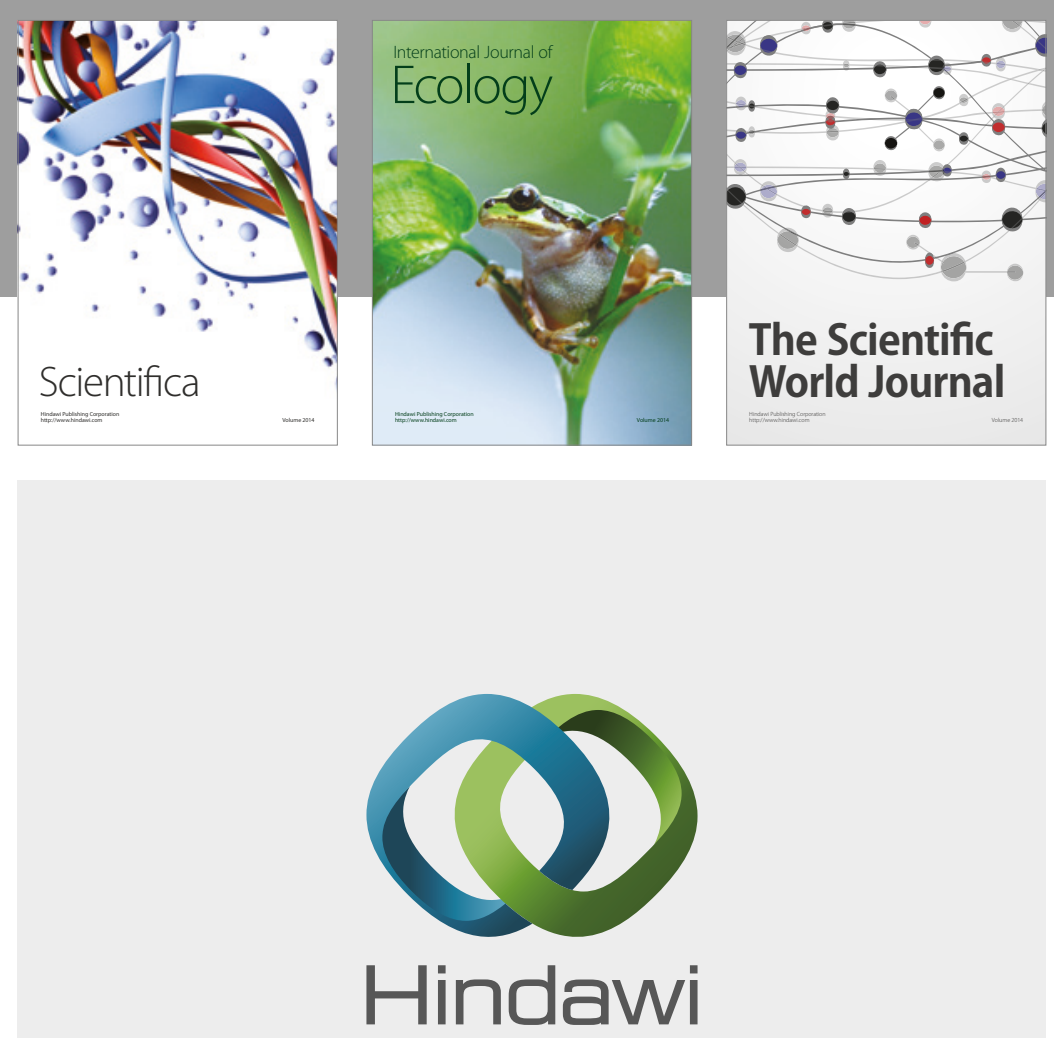

Submit your manuscripts at

https://www.hindawi.com
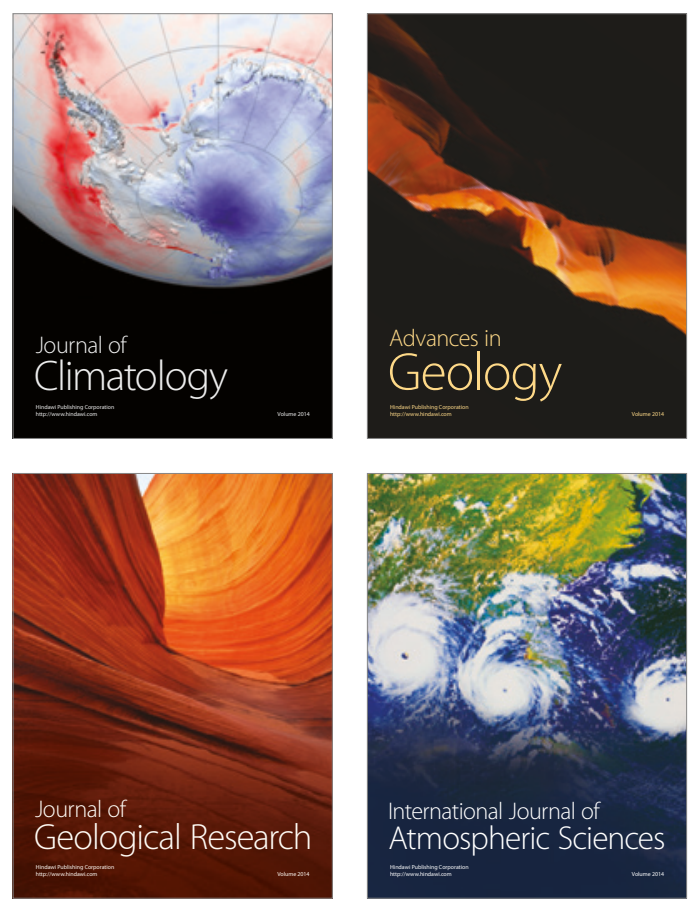

The Scientific

World Journal
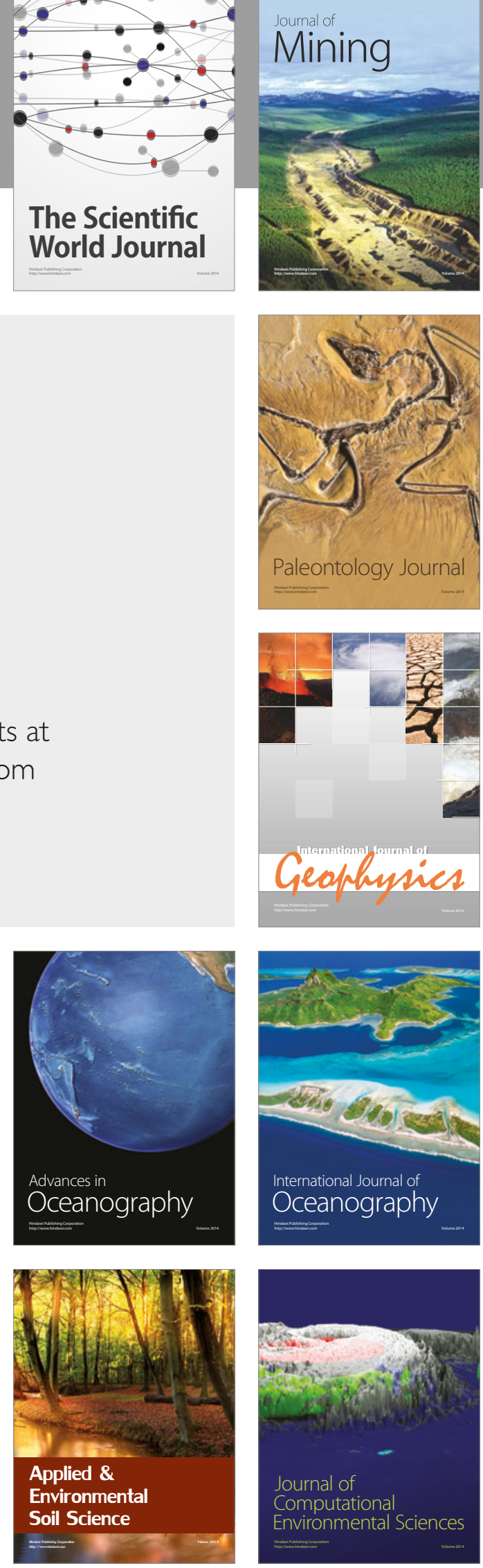